\title{
Co-emergence of Institutional Innovation Navigates the New Normal in Growing Economies
}

\author{
Weilin Zhao \\ Fujitsu Research Institute, Japan \\ Chihiro Watanabe \\ Tokyo Seitoku University, Japan \\ Yuji Tou \\ Tokyo Institute of Technology, Japan
}

\begin{abstract}
Increasing fear of the global simultaneous stagnation derived from the Euro-crisis together with the New Normal in growing economies reveals the limit of individual strength leading to the significance of fusion with global best practices. Dramatic advancement of the Internet has enabled consumers in any nation to choose and learn from world's strongest suppliers. Both trends inevitably necessitate co-emergence of institutional innovation between suppliers and consumers for sustainability. On the basis of an empirical analysis comparing institutional systems in 100 nations, this paper demonstrates the significance of this co-emergence thereby navigating the New Normal in growing economies.
\end{abstract}

Keywords: Co-emergence, institutional innovation, bi-polarization, new normal.

\section{INTRODUCTION}

$\mathrm{D}$ ramatic advancement of the internet beyond anticipation in terms of its diffusion speed and scope, has led to information technology (IT) driven economic development trajectory for different nations (MIC, 2012; Shinozaki, 2012; WEF, 2012).

This trajectory resulted in bi-polarization between IT growing economies and IT advanced economies (Fukuda et al., 2011). While the former economies enjoy a virtuous cycle between advancement of IT and its marginal productivity increase, the latter economies have fallen in a pit of a vicious cycle between them.

Only way of overcoming this paradox can be found by constructing a co-emergence of institutional innovation between two economies (Chew et al., 2010) by improving functionality development (FD) in IT growing economies by means of advanced IT initiated by IT advanced economies. This co-emergence beneficiates both economies by constructing co-evolutionary acclimatization trajectory common to both economies.

Given the increasing initiative in consumers in innovation game towards a post-excessive consumption society (McDonagh, 2008; Watanabe and Shin, 2009; Watanabe et al., 2011), this trajectory can be expected to be initiated by

Journal of Technology

Management for Growing Economies

Vol. 4 No. 1 April 2013 pp. 69-81

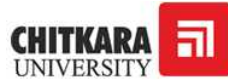

C 2013 by Chitkara University. All Rights Reserved. 
Zhao, W.

Watanabe, C.

Tou, Y. innovation and consumption co-emergence (Watanabe, et al., 2012b). Constructive navigation of the New Normal in growing economies can be thus anticipated.

To date, a number of studies have pointed out the significance of harnessing the vigor of emerging economies (e.g., Prahalad, 2004). However, these works attempted to find the solution within an individual system, and none has taken the perspective of a co-emergence of institutional innovation between the two types of economies with recognition of current bi-polarization structure.

On the basis of an empirical comparative analysis taking the development trajectories in 100 nations in the world and an examination of the institutional sources enabling sustainable growth in the foregoing paradox system, this paper attempts to demonstrate the foregoing hypothetical views and provide a constructive suggestion supportive to navigating the New Normal in growing economies.

Section two analyzes development trajectories in 100 nations. Section three conducts in-depth analysis of the way leading to innovation-consumption coemergence and an empirical analysis of the source of exceptional sustainable development in IT advanced economies. Section four briefly summarizes noteworthy findings, policy implications supportive to navigating the New Normal in growing economies and the points for future work.

\section{Developing Trajectories in IT Driven Economies}

Figure 1 demonstrates trend in global simultaneous dependency on IT. Dramatic advancement of the internet and subsequent mobile phone development have contributed significantly to enhance economic level in the world over the last decade between 2000 and 2010 as has been demonstrated in the dramatic improvement in the literate ratio of the world as illustrated on the left hand side of the Figure 1 (MIC, 2012). Such IT advancement has led to dramatic decrease in digital divide in the world as illustrated on the right hand side of the Figure 1 (Shinozaki, 2012). This decrease demonstrates global simultaneous dependency on IT.

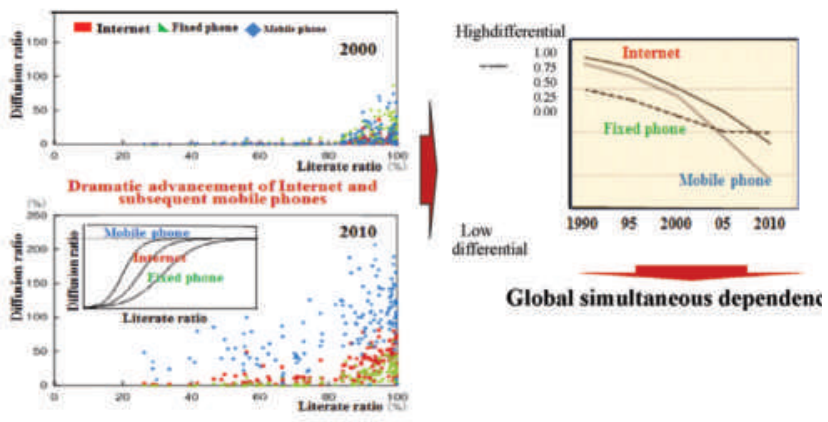

Figure 1: Trend in Global Simultaneous Dependency on IT. Source: White Paper on Japan's ICT (2012), Shinozaki (2012).

The level of worldwide advancement in IT can be traced by the Network

Journal of Technology Management for Growing Economies, Volume 4, Number 1, April 2013 
Readiness Index (NRI) measured by the World Economic Forum (WEF, 2012). NRI measures worldwide advancement in IT by computing following four dimensions:

(i) Environment (Political and regulatory environment, business and innovation environment),

(ii) Readiness (Infrastructure, digital content, and affordability),

(iii) Usage (Individual usage, business usage and government usage), and

(iii) Impact (Economic impact and social impact).

Table 1 tabulates the ranking of NRI in 100 nations in 2011. Looking at the Table, we note that Sweden demonstrates the highest score followed by Singapore, Finland, Denmark, Switzerland, Netherlands, Norway, United States, Canada and UK. Japan ranks 18 while other G7 nations as Germany, France and Italy rank 16, 23 and 48, respectively. Newly industrialized Asian tigers as Taiwan, Korea and Hong Kong rank 11, 12 and 13, respectively.Contrary to such higher rankings in Nordic countries, Singapore and majorities of G7 nations and Asian tiger, rankings in BRIC as Brazil, Russia, India and China remain lower ranking as 65, 56, 69 and 51, respectively.

Table 1: Networked Readiness Index in 100 Nations (2011)

\begin{tabular}{|c|c|c|c|}
\hline 1 SE Sweden 5.94 & 26 MT Malta 4.91 & $51 \mathrm{CN}$ China 4.11 & 76 MX Mexico 3.82 \\
\hline 2 SG Singapore 5.86 & 27 BH Bahrain 4.90 & 52 TR Turkey 4.07 & 77 TH Thailand 3.78 \\
\hline 3 F Finland 5.81 & 28 QA Qatar 4.81 & 53 MU Mauritius 4.06 & 78 MD Moldova 3.78 \\
\hline 4 DK Denmark 5.70 & 29 MY Malaysia 4.80 & 54 BN Brunei Darussalam 4.04 & 79 EG Egypt 3.77 \\
\hline 5 CH Switzerland 5.61 & 30 AE United Arab Emirates 4.77 & $55 \mathrm{KZ}$ Kazakhstan 4.03 & 80 ID Indonesia 3.75 \\
\hline 6 NL. Netherlands 5.60 & 31 LT Lithuania 4.66 & 56 RU Russian Federation 4.02 & 81 CV Cape Verde 3.71 \\
\hline 7 NO Norway 5.59 & 32 CY Cyprus 4.66 & 57 PA Panama 4.01 & 82 RW Rwanda 3.70 \\
\hline 8 US United States 5.56 & 33 PT Portugal 4.63 & 58 CR Costa Rica 4.00 & 83 VN Vietnam 3.70 \\
\hline 9 CA Canada 5.51 & 34 SA Saudi Arabia 4.62 & 59 GR Greece 3.99 & 84 BA Bosnia and Herzegovina 3.65 \\
\hline 10 UK United Kingdom 5.50 & 35 BB Barbados 4.61 & 60 TT Trinidad and Tobago 3.98 & 85 CS Serbia 3.64 \\
\hline 11 TW Taiwan, China 5.48 & 36 PR Puerto Rico 4.59 & 61 AZ Azerbaijan 3.95 & 86 PH Philippines 3.64 \\
\hline 12 KR Korea, Rep. 5.47 & 37 SI Slovenia 4.58 & 62 KW Kuwait 3.95 & 87 DM Dominican Republic 3.60 \\
\hline 13 HK Hong Kong SAR 5.46 & 38 ES Spain 4.54 & 63 MN Mongolia 3.95 & 88 GE Georgia 3.60 \\
\hline 14 NZ New Zealand 5.36 & 39 CL Chile 4.44 & 64 SK Slovak Republic 3.94 & 89 BW Botswana 3.58 \\
\hline 15 is Iceland 5.33 & $40 \mathrm{OM}$ Oman 4.35 & 65 BR Brazil 3.92 & 90 GY Guyana 3.58 \\
\hline 16 DE Germany 5.32 & 41 LV Latvia 4.35 & 66 MK Macedonia, FYR 3.91 & 91 MA Morocco 3.56 \\
\hline 17 AU Australia 5.29 & 42 CZC Crech Republic 4.33 & 67 RO Romania 3.90 & 92 AR Argentina 3.52 \\
\hline 18 JP Japan 5.25 & 43 HU Hungary 4.30 & 68 AL Albania 3.89 & 93 KE Kenya 3.51 \\
\hline 19 AT Austria 5.25 & 44 UY Unuguay 4.28 & 69 IN India 3.89 & 94 AM Armenia 3.49 \\
\hline 20 II. Israel 5.24 & 45 HR Croatia 4.22 & 70 BG Bulgaria 3.89 & 95 LB Lebanon 3.49 \\
\hline 21 LU Luxembourg 5.22 & 46 ME Montenegro 4.22 & 71 LK Sri Lanka 3.88 & 96 EC Ecuador 3.46 \\
\hline 22 BE Belgium 5.13 & 47 JO Jordan 4.17 & 72 ZA South Africa 3.87 & 97 GH Ghana 3.44 \\
\hline 23 FR France 5.12 & 48 IT Italy 4.17 & 73 CO Colombia 3.87 & 98 GT Guatemala 3.43 \\
\hline 24 EE Estonia 5.09 & 49 PL. Poland 4.16 & 74 JM Jamaica 3.86 & 99 HN Honduras 3.43 \\
\hline 25 IE Ireland 5.02 & 50 TN Tunisia 4.12 & 75 UA Ukraine 3.85 & 100 SN Senegal 3.42 \\
\hline
\end{tabular}

Source: The Global Information Technology Report 2012 (World Economic Forum, 2012).

Foregoing observations suggest that economic development level in 100 nations tabulated in Table 1 can be depicted by a function of $N R I$ as follows:

$$
\frac{V}{P}=F(N R I)
$$


Zhao, W.

Watanabe, C.

Tou, Y. where V/P: GDP per capita at fixed prices.

Taylor expansion to the first term:

$$
\text { h } V / P=a+b \text { h NRI }
$$

where $a$ and $b$ : coefficients.

$$
\begin{aligned}
\ln V / P & =3.47+4.25 \ln N R I+1.03 D_{1}-1.12 D_{2} \quad \text { adj. } R^{2} 0.876 \\
(10.62)(19.47) & \text { (9.31) }(-9.29)
\end{aligned}
$$

where $D_{1}$ and $D_{2}$ are dummy variables as $D_{1}: 8$ nations with extreme lower level of $N R I$ than $V / P($ Qatar, Luxemburg, Kuwait, Brunei, UAE, Norway, Italy and Greece $)=1$, other nations $=0 ; \mathrm{D}_{2}: 8$ nations with extreme higher level of $N R I$ than $V / P($ Sweden, Israel, New Zealand, Finland, Jordan, Korea, Estonia and Malaysia) $=1$, other nations $=0$.

This analysis demonstrates that economic development level in the current world is governed largely by the advancement of IT and suggests that the economic development trajectories in these nations can largely be attributed to the level of IT.

Prompted by these observations, Figure 2 demonstrates economic development trajectory in 100 nations taking logistic growth function initiated by NRI.

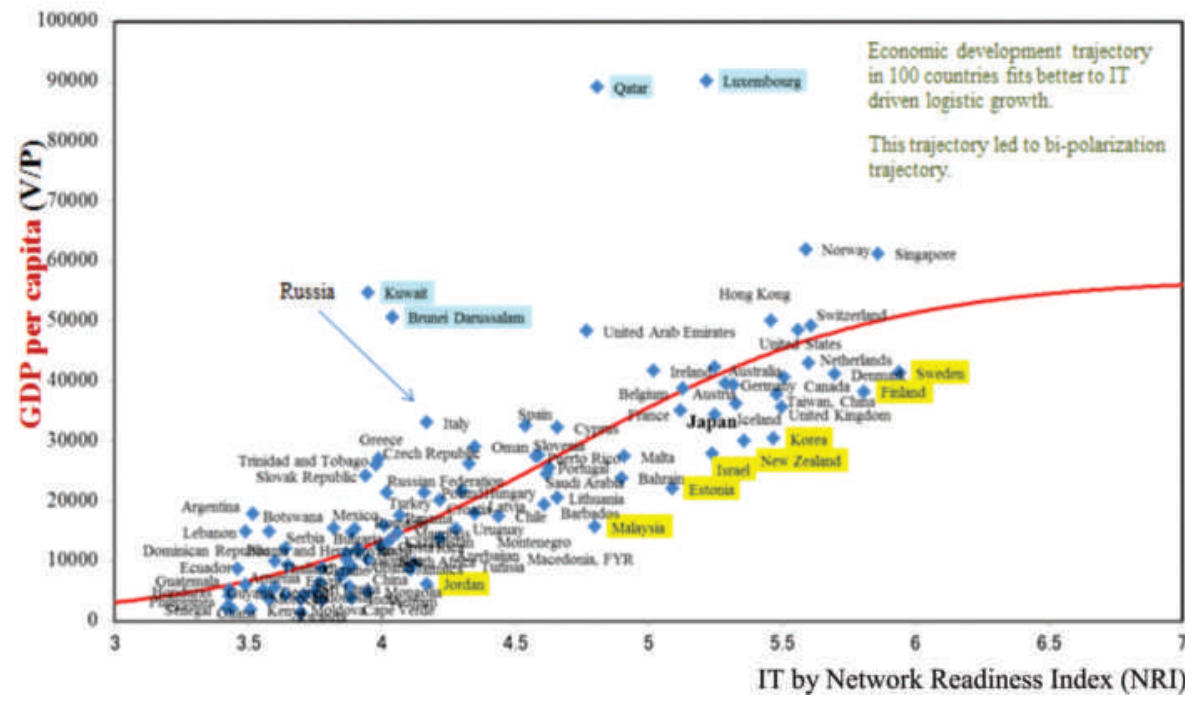

Figure 2: IT Driven Economic Development Trajectory in 100 Nations (2011). 
Figure 2 demonstrates that economic development trajectory in 100 nations fit better to IT driven logistic growth function as follows:

$$
Y \equiv \frac{V}{P}=\frac{N}{1+e^{-a N R I+b}}+c D_{1}+d D_{2}
$$

Where $N$ : carrying capacity; $D_{1}$ and $D_{2}$ : dummy variables corresponding to the preceding analysis; and $a, b, c$ and $d$ : coefficients.

Similar to the preceding analysis, empirical analysis taking 100 nations in 2011 is demonstrated as follows:

\begin{tabular}{|ccccc|c|}
\hline$N$ & $a$ & $b$ & $c$ & $d$ & \\
\hline 57239 & 1.68 & -7.90 & 46434 & -12913 & adj. $R^{2} 0.88$ \\
\hline & & & & \\
\hline$(9.62)$ & $(7.58)$ & $(-9.80)$ & $(14.54)$ & $(-5.25)$ & \\
\hline
\end{tabular}

Since logistic growth trajectory can be developed to a bi-polarization trajectory as follows (Tokumasu and Watanabe, 2008), foregoing analysis suggests that IT driven economic development trajectory in 100 nations splits to bipolarization as demonstrated in Figure 3.

$$
\begin{aligned}
& \frac{d Y}{d t}=a Y\left(1-\frac{Y}{N}\right)=\frac{a N}{1+e^{-a t-b}}\left(1-\frac{1}{1+e^{-a t-b}}\right)=\frac{a N}{\left(1+e^{-a t-b}\right)} \cdot \frac{e^{-a}}{(1+e} \\
& =\frac{a N}{\left(1+e^{-a t-b}\right)} \cdot \frac{1}{\left(1+e^{a t+b}\right)}=\frac{a N}{\left(2+e^{-a t-b}+\frac{1}{e^{-t-b}}\right)} \\
& \frac{a N}{\frac{d Y}{d t}}=2+e^{-a t-b}+\frac{1}{e^{-a t-b}} \\
& y=(1+x)+\left(1+\frac{1}{x}\right) \quad y \equiv \frac{a N}{\frac{d Y}{d t}}, x \equiv e^{-a t-b}
\end{aligned}
$$

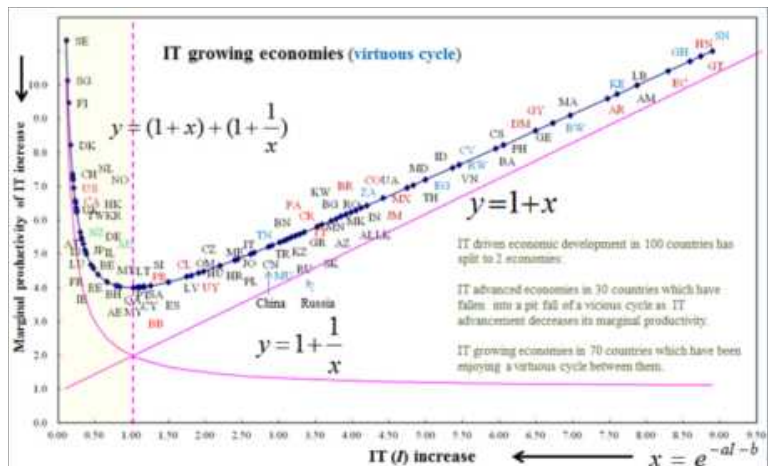

Figure 3: Bi-polarization of IT Driven Economic Development Trajectory in 100 Nations (2011). 
Watanabe, C.

Tou, Y.
Zhao, W.

Looking at Figure 3 we note that IT driven economic development trajectory in 100 nations has split into two economies. While, among the IT growing nations 70 (nations with NRI ranking 31 to 100 in Table 1) have been enjoying a virtuous cycle between IT advancement and its marginal productivity increase, 30 advanced IT nations (NRI ranking 1 to 30 ) have fallen into a pit of a vicious cycle as IT advancement decreases its marginal productivity.

Such a bi-polarization necessitates co-emergence of institutional innova74 tion between two types of economies in such a way as advanced IT enabled by IT advanced economies improves functionality development (FD) in IT growing economies. This increases marginal productivity of IT in these economies leading to their economic growth enabling IT advanced economies harness the vigor of IT growing economies as illustrated in Figure 4.

$Y=\mathrm{F}(\mathrm{X}, \mathrm{I}) \boldsymbol{Y}=\boldsymbol{V} / \boldsymbol{P}$ (GDP per capita), $\boldsymbol{X}$ : labor and capital, $\boldsymbol{I}$ : Level of IT by $\boldsymbol{N R \boldsymbol { I }}$

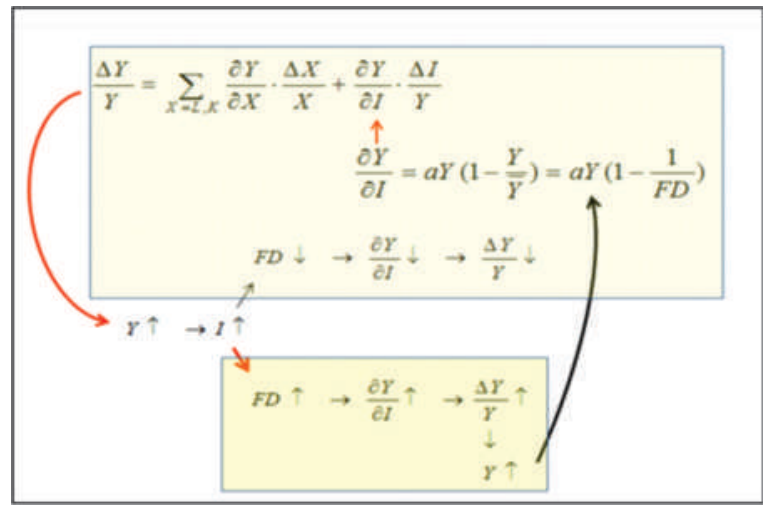

IT advanced economies

Figure 4: Basic Concept of Co-emergence of Institutional Innovation between IT Advanced Economies and IT Growing Economies.
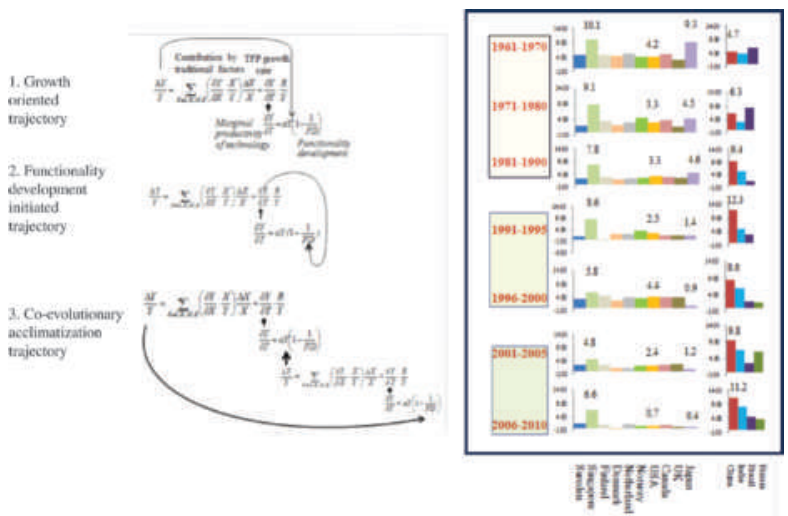

Figure 5: Global Change in Growth Engine Sources: IMF database and World Bank indicators (annual issues). 
Such a trajectory leading co-emergence of institutional innovation between two types of economies can be called "co-evolutionary acclimatization trajectory." Both economies can maintain respective sustainable growth by constructing a virtuous cycle between them through mutual inspiration and acclimatization of comparative advantages of the partner.

The significance of such a co-evolutionary acclimatization trajectory for co-emergence of institutional innovation between two economies under the current bi-polarization structure is examined, Figure 5. It compares trend in global change in growth engine over the last half century taking 10 leading nations in current IT advanced economies and BRIC countries (Brazil, Russia, India and China) which, belong to current IT growing economies. Growth engine is examined by analyzing key driving mechanism enabling a conspicuous development in each historical era.

Looking at Figure 5 we note that over the first 3 decades (1961-1990) Japan (together with Singapore) demonstrated a conspicuous economic growth based on "growth oriented trajectory". This harnessesed their own vigor for further innovation for sustainable growth (Chen and Watanabe, 2007; Watanabe et al., 2006). During this period Japan initiated growth engine was appraised as a source of "Japan as No. 1" and also "Japan's high-technology miracle."

This notable growth engine, however, faded out in the 1990s as paradigm shifted from an industrial society to an information society and subsequent mature economy (Watanabe, 2009). Contrary to Japan's decline, USA demonstrated contrasting growth by utilizing the advantage of digital economy (Kondo et al., 2007). This can be attributed to "functionality development initiated trajectory" that induces growth engine by creating new functionality rather by quantitative increase in economy (Watanabe and Shin, 2009).

This growth engine also faded out in this century, particularly in the letter half of the first decade of this century (Watanabe et al., 2012a). Economic growth in almost all of leading countries in IT advanced economies except Singapore has stagnated during this period. Contrary to such stagnation in IT advanced economies (except Singapore), conspicuous growth has not been observed in a few countries in growing IT economies, particularly in China and India. This contrast corresponds to a contrast of a virtuous cycle in IT growing economies and a vicious cycle in IT advanced economies with respect to advancement of IT and its marginal productivity increase as demonstrated in Figure 3.

Foregoing observations remind us the limit of "growth oriented trajectory" and "functionality development initiated trajectory" that functioned effectively in current IT advanced economies in the last century. Consequently, these
Co-emergence of Institutional 
Watanabe, C.

Tou, Y.
Zhao, W.

observations resulted in revealing the limit of individual strength and leading us to realize the significance of co-evolutionary acclimatization trajectory for co-emergence of institutional innovation between IT growing economies and IT advanced economies under the current bi-polarization structure between them.

\section{Innovation-Consumption Co-emergence} functionality development in IT growing economies for global sustainability by constructing a co-evolutionary acclimatization trajectory worldwide under the current bi-polarization structure.

Given the increasing initiative in consumers in innovation game toward a post-excessive consumption society (McDonagh, 2008; Watanabe and Shin, 2009, Watanabe et al., 2011) and New Normal, dynamism for this improvement can be revealed by analyzing the leading role of functionality development in advancing utility function that induces sustainable growth significantly. The role of IT support to IT growing economies by IT advanced economies can be identified in this context of the analysis.

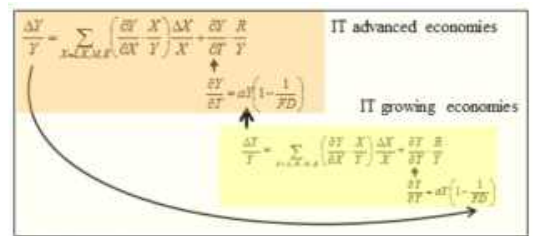

Utility function

$U=U(F D)=U(Y, Q)=\frac{\partial U}{\partial Y} \cdot Y+\frac{\partial U}{\partial Q} \cdot Q=\left(\frac{\partial U}{\partial C} \cdot C\right)\left(\frac{\partial C}{\partial Y} \cdot \frac{Y}{C}+\frac{\partial C}{\partial Q} \cdot \frac{Q}{C}\right)=\left(\frac{\partial U}{\partial C} \cdot C\right)\left[\frac{\partial C}{\partial Y} \cdot \frac{Y}{C}+\left(\frac{\partial C}{\partial I} \cdot \frac{I}{C}\right)\left(\frac{\partial I}{\partial Q} \cdot \frac{Q}{I}\right)\right]$

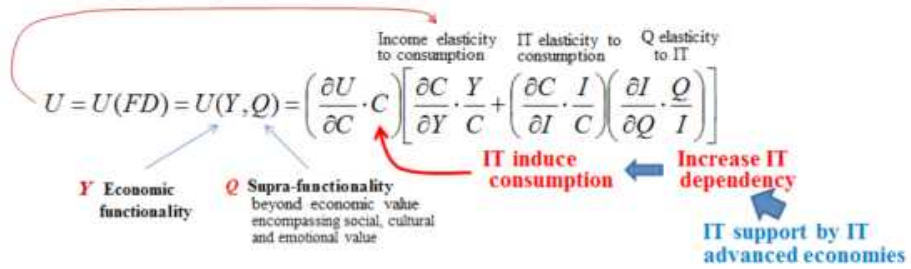

Figure 6: IT Driven Innovation-Consumption Co-emergence Dynamism

Prompted by such perspective, Figure 6 outlines IT driven innovationconsumption co-emergence dynamism. It is generally postulated that consumers preference has been steadily shifting from economic functionality driven preference $(Y)$ to supra-functionality beyond economic value driven preference $(Q)$ (JCO, 2005 and McDonagh, 2008). Here supra-functionality beyond economic value encompasses social, cultural and emotional values. Such a shift can be observed clearly by Public Opinion Survey Concerning 
People's Lifestyles', conducted annually by Japan's Cabinet Office (JCO) as illustrated in the upper right of the Figure 6.

With such understanding, utility function that represents gratification of consumption essential for economic growth can be depicted by a function of $Y$ and $Q$ composing of (i) marginal consumption to utility, (ii) consumption, (iii) income elasticity to consumption, (iv) IT elasticity to consumption, and (v) $Q$ elasticity to IT as depicted in the lower part of Figure 6.

While increasing trend in $Q$ has been inducing IT dependency ( $Q$ elasticity to IT effect), advancement of IT cannot be managed by IT growing economies. Such constraints can be expected to be removed by IT support by IT advanced economies leading to dramatic increase in IT induced consumption (IT elasticity to consumption effect) and enhances utility level which in turn further induces consumption (income elasticity to consumption effect) leading to IT driven innovation-consumption coemergence under the condition of IT support by IT advanced economies.

Such co-emergence in IT growing economies benefits IT advanced economies by providing increasing opportunity in harnessing the vigor of IT. In a stagnating economic environment IT option results in accelerating stagnation by decreasing its marginal productivity.

IT driven co-emergence of institutional innovation between two economies is enabled by constructing a co-evolutionary acclimatization trajectory. Figure 7 illustrates such dynamism.

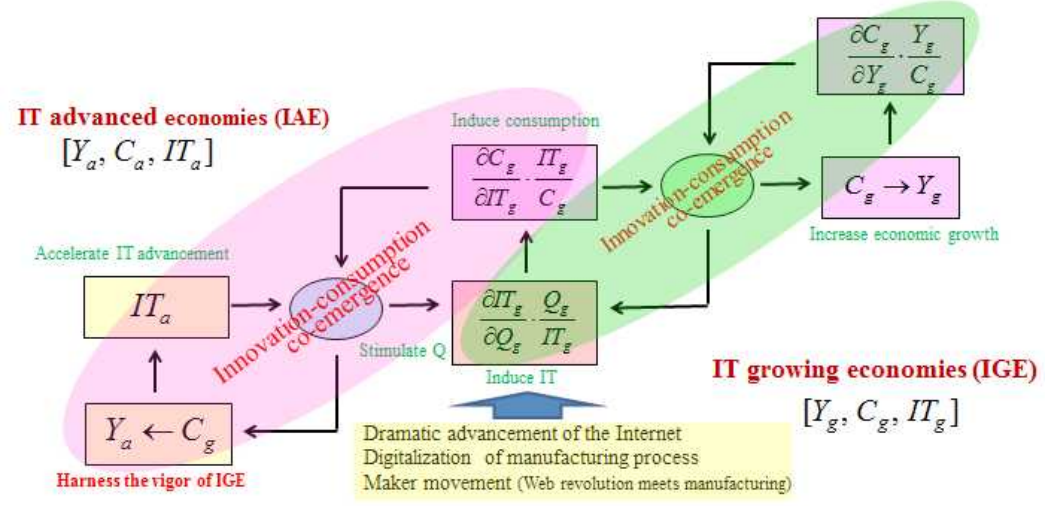

Figure 7: Dynamism Inducing Innovation-Consumption Co-emergence. Advancement of IT initiated by IT advanced economies (IAE) stimulates increasing preference of supra-functionality beyond economic value $(Q)$ in 
Zhao, W.

Watanabe, C.

Tou, Y.
IT growing economies (IGE). This preference is accelerated by such noteworthy stream as dramatic advancement of the Internet, digitalization of manufacturing process, and maker movement. Stimulated $Q$ in IGE induces its further IT dependency inducing its consumption. While this inducement provides opportunity for IAE to harness the vigor of IGE enabling further advancement of IT, this inducement also increases economic growth in IGE leading to further increase in its consumption demand inducing further $Q$ elasticity to IT leading to constructing a dual innovation-consumption co-emergence crossover two economies.

Such a dual innovation-consumption co-emergence can be observed in Singapore's development trajectory as demonstrated in its NEWater (recycled water) development dynamism as illustrated in Figure 8. Securing water is a crucial survival strategy for Singapore (Chew et al., 2010). In order to accomplish this survival strategy, Singapore endeavored to explore technology driven water starting from importing advanced membrane technology from USA and Japan (Phase 1). Then it endeavored to transit from learning to indigenous technology development (Phase 2). It further endeavored to accelerate exporting of developed indigenous technology (Phase 3) and co-evolutionary acclimatization of global best practices through exporting activities (Phase 4).

Based on such a stepwise endeavor, Singapore has succeeded to supply $40 \%$ of total water demand by technology driven water consisting of NEWater (30\%) and desalination (10\%). It will attempt to double increase such dependency to double by 2061 (50\% on NEWater and 30\% on desalination).

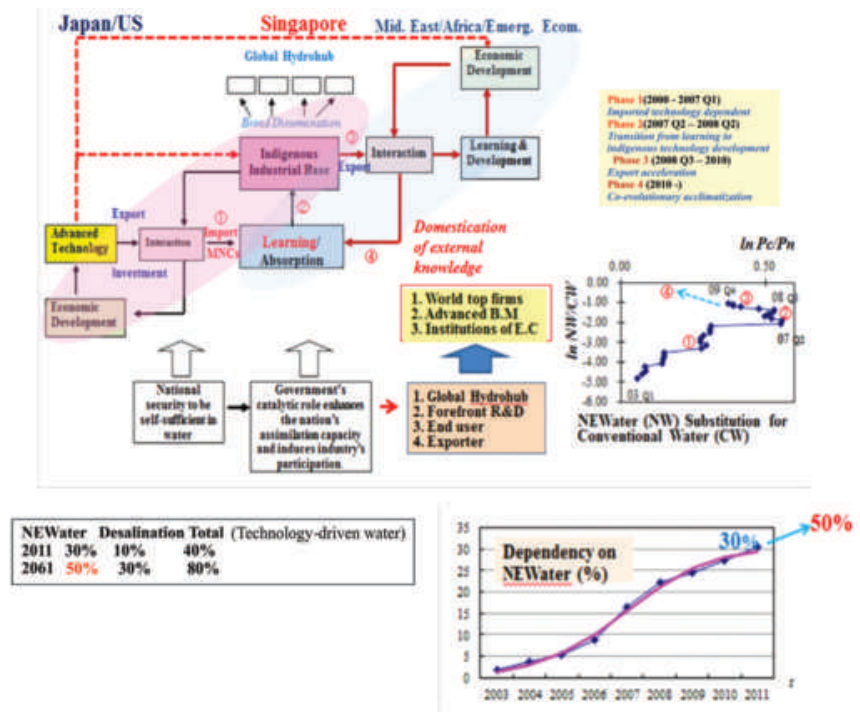

Figure 8: NEWater Development Dynamism in Singapore 
Through the course of accomplishing such survival strategies Singapore has created dual innovation-consumption co-emergence structure which can be considered the source of enabling it exceptional by sustainable growth despite bi-polarization structure resulting in stagnating sustainable growth in IT advanced economies as reviewed in Figure 5.

\section{CONCLUSION}

This paper has attempted to explore the way for co-emergence of institutional innovation that navigates the New Normal in growing economies. This exploration has been carried out under the limited individual strength revealed by the increasing fear of the global simultaneous stagnation derived from the Euro-crisis together with the New Normal in growing economies and subsequent increasing significance of fusion between individual strength with global best practices

An empirical analysis focusing on the development trajectories and their growth engine in 100 nations in the world was carried out. Also, an examination of the institutional sources enabling sustainable growth in the current bipolarization structure was conducted.

Noteworthy findings obtained include:

(i) While dramatic advancement of the Internet has enabled global simultaneous dependency on IT, it has resulted in bi-polarization between IT advanced economies and IT growing economies.

(ii) While the latter economies enjoy a virtuous cycle between IT advancement and its marginal productivity increase, the former economies have fallen in a pit of a vicious cycle between them.

(iii) This necessitates a co-emergence of institutional innovation between the two types of economies to ensure their sustainability.

(iv) This co-emergence can be accomplished by a co-evolutionary acclimat zation trajectory between two economies.

(v) Given the increasing initiative of consumers in innovation and global stagnation of consumption, co-emergence of innovation and consumption will play a decisive role in navigating this trajectory.

These findings provide the following constructive suggestion supportive to navigating both economies in a bi-polarization structure, particularly the New Normal in growing economies:

(i) Both economies should realize the limit to individual strength and
Co-emergence of Institutional

Journal of Technology Management for Growing Economies, Volume 4, Number 1, April 2013 
Zhao, W.

Watanabe, C.

Tou, Y. significance of fusion with global best practices.

(ii) Both economies should make every effort in constructing a co-evolu tionary acclimatization trajectory.

(iii) Such trajectory can be anticipated to be accelerated by stimulating innovation - consumption co-emergence.

Further work should endeavor to examine noteworthy success in such a coemergency given the hierarchy structure of institutional systems consisting of national, industry, sector, firm and individuals.

\section{REFERENCES}

Chen, C and Watanabe, C. (2007) 'Competitiveness through Co-evolution between Innovation and Institutional Systems: New Dimensions of Competitiveness in a Service-oriented Economy', Journal of Services Research, 7:2, pp. 27-55.

Chew, M, Watanabe, C. and Tou, Y. (2010) 'Technology Leapfrogging Findings from Singapore's Water Industry', Journal of Technology Management for Growing Economies, 1:2, pp. 29-47.

Fukuda, K, Zhao, W. and Watanabe, C. (2011) 'Dual Hybrid Management of Technology: Coevolution with Growing Economies', Journal of Technology Management for Growing Economies, 2:1, pp. 9-26.

IMF. (2012) 'World Economic Outlook Database', IMF, Washington DC.

Japan's Cabinet Office (JCO). (2005) 'Public Opinion Survey Concerning People's Lifestyles', JCO. Tokyo.

Kondo, R., Watanabe, C. and Moriyama, K. (2007) 'A Resonant Development Trajectory for IT Development: Lessons from Japan's i-mode', International Journal of Advances in Management Research, 4:2, pp. 7-27. http://dx.doi.org/10.1108/97279810780001255.

McDonagh, D. (2008) 'Satisfying Needs beyond the Functional: The Changing Needs of the Silver Market Consumer', Proceedings of the International Symposium on the Silver Market Phenomenon, Tokyo.

Ministries of Internal Affairs and Communication (MIC). (2012) 'White Paper on Japan's Information and Communication Technology', MIC, Tokyo.

Prahalad, C.K. (2004) 'The Fortune at the Bottom of the Pyramid: Eradicati ng Poverty through Profits', Wharton School Publishing, New Jersey.

Shinozaki, A. (2012) 'Advancement of IT Overthrows Poverty Trap', Nihon KeizaiShinbun (Nikkei Daily news), Nov. 1, pp. 28.

Tokumasu, S. and Watanabe, C. (2008) 'Institutional Structure Leading to the Similarity and Disparity in Innovation in EU 15 Countries', Journal of Services Research, 8:1, pp. 5-42.

Watanabe, C., Asgari, B. and Nagamatsu, A. (2003) 'Virtuous Cycle between R\&D Functionality Development and Assimilation Capacity for Competitive Strategy in Japan's High-technology Industry', Technovation, 23:11, pp.879-900. http://dx.doi.org/10.1016/ S0166-4972(02)00041-X.

Watanabe, C., Takahashi, H., Tou, Y. and Shum, K.L. (2006) 'Inter-fields Technology Spillovers Leveraging Co-evolution between Core Technologies and their Application to New Fields', Journal of Services Research, 6:2, pp. 7-24.

Watanabe, C. (2009) 'Managing Innovation in Japan: The Role Institutions Play in Helping or Hindering How Companies Develop Technology', Springer, Berlin. http://dx.doi.

Journal of Technology Management for Growing Economies, Volume 4, Number 1, April 2013 
org/10.1007/978-3-540-89272-4

Watanabe, C., Moriyama, K. and Shin, J.H. (2009) 'Functionality Development Dynamism in a Diffusion of Technology: A Case of Japan's Mobile Phones Development', Technological Forecasting and Social Change, 76:6, pp. 737-753. http://dx.doi.org/10.1016/j.techfore.2008.06.001.

Watanabe, C. and Shin, J.H. (2009) 'Co-evolutionary Dynamism between Innovation and Institutional Systems: The Rise and Fall of the Japanese System of Management of Technology', in C. Watanabe (ed.), The Science of Institutional Management of Technology, Tokyo Institute of Technology, pp. 21-34.

Watanabe, C., Shin, J.H., Heikkinen, J., Zhao, W. and Griffy-Brown, C. (2011) 'New Functionality Development through Follower Substitution for a Leader in Open Innovation', Technological Forecasting and Social Change, 78:1, pp. 116-131. http://dx.doi.org/10.1016/j. techfore.2010.04.019.

Watanabe, C., Kanno, G. and You, Y. (2012a) 'Inside the Learning Dynamism Inducing the Resonance between Innovation and High-demand Consumption: A Case of Japan's High-functional Mobile Phones', Technological Forecasting and Social Change, 79: 7, pp. 12921311. http://dx.doi.org/10.1016/j.techfore.2012.03.003

Watanabe, C., Zhao, W. and Nasuno, M. (2012b) 'Resonance between Innovation and Consumers: Suggestion to Emerging Market Consumers', Journal of Technology Management for Growing Economies, 3:1, pp. 7-31.

World Bank. (2012) 'World Bank Indicators', World Bank, Washington DC.

World Economic Forum (WEF). (2012) 'The Global Information Technology Report 2012', WEF. Geneva.

Weilin Zhao, is Research Associate, Center of Waseda Business School, Waseda University. Email: weilinzhao.chen@ gmail.com.

Chihiro Watanabe, is Professor, Department of Industrial Management Tokyo Seitoku University, Tokyo. Email: watanabe.c.pqr@gmail.com.

Yuji Tou, Ph.D., is Researcher of Graduate School of Modern Society and Culture, Niigata University, Tokorozawa-shi, Saitama, Japan. Email: tou. yuji@gmail.com.
Co-emergence of Institutional 